\title{
The E-Government: A Jigsaw View
}

\author{
Adeel Ghayur \\ 1 H2O Power Pvt. Ltd. Islamabad-Pakistan www.h2opower.com.pk \\ adeel@h2opower.com.pk
}

\begin{abstract}
E-Government, today, is being regarded as the panacea for many of the conventional government ills, such as rampant corruption in developing countries to costly service deliveries in the developed countries. This paper provides a quick introduction to the e-government and proceeds on to describe a new framework developed for the transition of a government into an egovernment - more specific to the environment of a developing country like that of Pakistan. This model draws parallel to a jigsaw, thus has been called the Jigsaw Model. The fundamental strength of this model lies in the fact that it has acknowledged the society as a foundation pillar in the e-government model and the entire economy progresses with the coalescence of all four parties included.
\end{abstract}

Keywords: E-Government, e-governance theory, e-economy model, Jigsaw Model

\section{Introduction}

E-Government has an enormous potential in terms of improving service delivery and efficiency, better response to business and citizen needs, and providing affordable government services. Defined as "Government's use of technology, particularly webbased Internet applications, to enhance the access to and delivery of government information and service to citizens, business partners, employees, other agencies, and government entities [5]", the e-government makes possible for its different departments and organizations to have direct access to grassroots and vice-versa. While, it cuts down the costs and delivery times for the government it also becomes a tool for check and balances against the government in the hands of the citizens. The e-government thus also acts as a tool for good governance - transparency, participation, regulations and accountability. It may also be defined as "the continuous optimization of service delivery, constituency participation, and governance by transforming internal and external relationships through technology, the Internet, and new media [3]".

The two main applications of e-government are e-services and e-transactions. Though the geographical area makes implementation of the aforementioned 
applications less efficient for a government than for private sector firms [8] as companies can do business outside their national boundaries thus increasing their customer base however, the governments can make it up with the size of their population. This is especially true for countries like Pakistan having sizeable population -150 million.

Based on the activity, e-government has been divided into four distinct areas, namely: e-democracy, e-service provision, e-management, and e-governance [7]. And based on interactions we have divided e-government into three categories, namely: government and business ( $\mathrm{GnB}$ ), government and citizen ( $\mathrm{GnC}$ ), and government and government $(\mathrm{GnG})$, which are further divided into government to business $(\mathrm{G} 2 \mathrm{~B})$ and business to government $(\mathrm{B} 2 \mathrm{G})$, government to citizen $(\mathrm{G} 2 \mathrm{C})$ and citizen to government $(\mathrm{C} 2 \mathrm{G})$, and government to government $(\mathrm{G} 2 \mathrm{G})$ nationally and internationally respectively (Fig. 1). This division is based on the flow of services in one direction and flow of money in the other. For example civil servants working in government would be considered under $\mathrm{C} 2 \mathrm{G}$ category.

\section{E-Government}

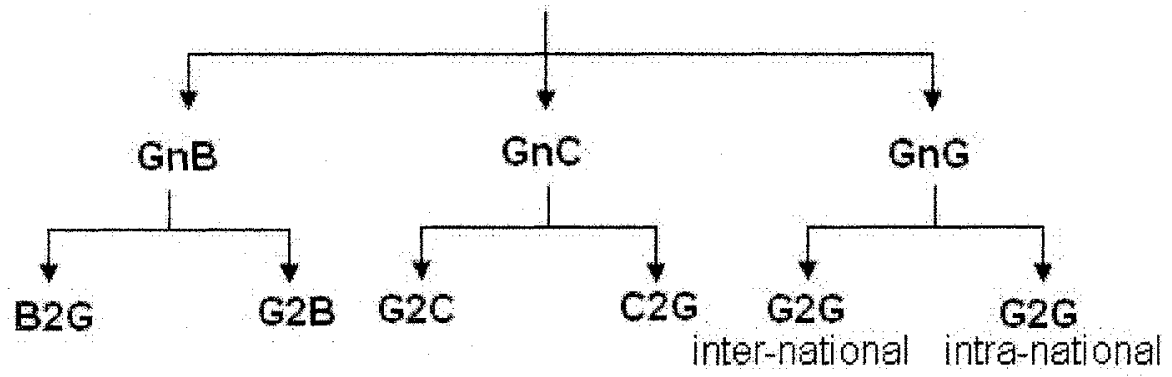

Fig. 6. E-Government categories based on interactions. The division is based on the flow of services in one direction and flow of money in the other.

This paper attempts to develop a framework for transition of a government into an e-government - more specific to the environment of a country like Pakistan. The paper first looks at different e-government theories in section 2 followed by description of three different types of e-economy models in section 3 . Then the paper focuses on the core of the paper, the Jigsaw Model in section 4 and the paper closes with some concluding remarks in section 5 .

\section{E-Governance Theories}

There is a growing sense towards the impact of today's Information and Communication Technology (ICT) tools on governance. It is not the tools themselves which are in question rather the use of these tools and the intentions preceding them. Usually these intentions are encompassed into four rival theories as discussed by Perri 6 [6] primarily based on the results they would materialize into. 
However, after restructuring we have divided them into five. A look at these theories is needed to provide us with a view of what the possible end results are of implementing an e-government.

\subsection{Rainbow Theory}

This theory also called Rationalism Theory dictates that the ICT tools will be utilized to help in better decision making and optimization of the governance processes. The theory is further divided based on the two trends it might follow. The first theory, Primary Rainbow Theory states that the governments would implement egovernance by following the popular trends and adopting the ways of the leaders in e-governance. The second theory, namely: Supernumerary Rainbow Theory states that the governments would utilize the latest tools to implement e-governance but at the same time will take steps to keep the cultural and traditional heritage and values within the community rather than submitting to the overflowing outside influences as in case of Primary Rainbow Theory.

\subsection{Kytoon Theory}

Kytoon or Control Theory implies that the e-government tools would be used for better control of the populace. This theory is based on the concept of "information is control".

\subsection{Smog Theory}

Also called the Noise Theory; it is based on the argument that e-government tools such as Internet provide too much information for governance procedures such as decision making, hence ultimately piling up more problems than solving the piled ones. This view wholly rejects the cybernetic faith that information is control [6].

\subsection{Virga Theory}

Virga Theory implies that implementation of ICT tools will not have much impact on the governance. However, the government would still benefit from the potential of ICT tools such as speeding up of information and service deliveries. This theory states that changes in governance and government are socially and politically driven and Internet is one of the means. There is a thin line between Rainbow and Virga Theory. In Rainbow Theory the effective utilization of ICT tools requires changes within the government itself, which the government would carry out. Conversely, the Virga Theory states that a country might implement ICT tools but without requiring any changes in the government and not having a notice worthy impact. 


\subsection{Tempest Theory}

Tempest or Chaos theory implies that e-government tools such as Internet would make a government loose control - mainly by malpractices.

\section{E-Economy Models}

Looking at the transformations of different economies into e-economies we have categorized their structures into three distinct e-economy models. Each model is comprised of three parties, namely: citizen, e-government, and e-business. The three models are differentiated based upon the roles three parties play and their respective structures. The shape and structure of an e-government depends upon the e-economic model a country is moving towards or is in the process of implementation and the egovernance theory which it has adopted as its underlying ideology or is inevitably heading towards. The three models are briefly discussed below.

\subsection{E-Business Core Model}

It is the dominant e-economy model in which the government and the economy are restructured in such a way that businesses can make the best out of today's ICT revolution (Fig. 2). Businesses are the main driving force behind the transition of the government towards e-government. The government starts its journey towards egovernment mainly by facilitating the implementation of ICTs for the businesses and in due process evolves into an e-government itself.

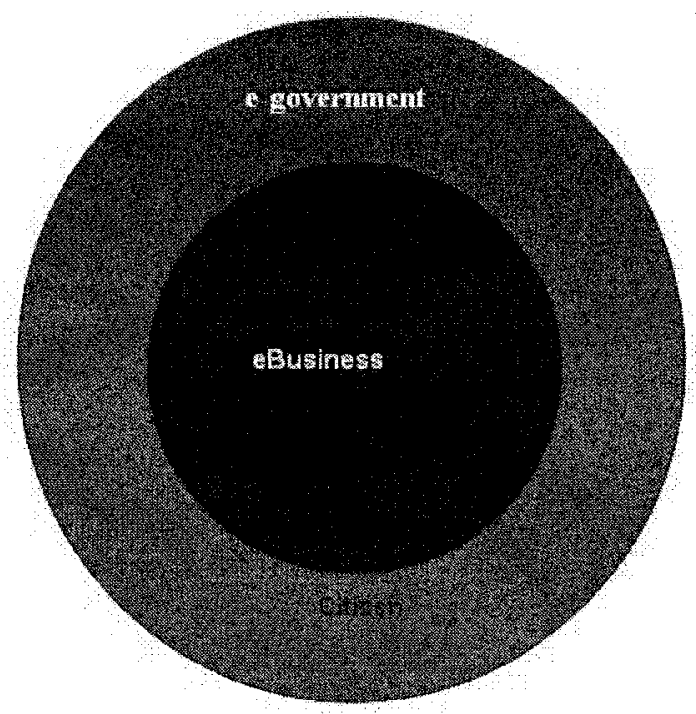

Fig. 2. E-Business Core Model. In the figure we can see e-business at the core of the model and the citizen and e-government structured around it. 


\subsection{E-Government Core Model}

In E-Government Core Model (Fig. 3) the ICT tools are utilized and implemented mainly by the government. The businesses on the whole might still be operating in a pre-ICT era, while the e-government continues its evolution alongside the emergence of new ICTs. As a result of improvements within the governmental functions the businesses and citizens receive the benefits as well, and the businesses follow a similar path towards e-business.



Fig. 3. E-Government Core Model. In the figure we can see the e-government at the core of the e-economy model.

\subsection{Hierarchical E-Government Model}

In every e-government model the hierarchical governmental structure is broken down into a flatter one, except here. In this e-economy model the government keeps its traditional hierarchical structure sitting at top of citizens and businesses (Fig. 4). The government adopts the ICTs to improve its efficiency between its hierarchies. The citizens and businesses also benefit as a result of ICT implementation in the government but the benefits to the two groups are the least in comparison to other models. Additionally the adoption of ICTs within the government do not provide any guarantee or incentives for the businesses to embellish themselves with these tools of twenty-first century, unlike in other models. 


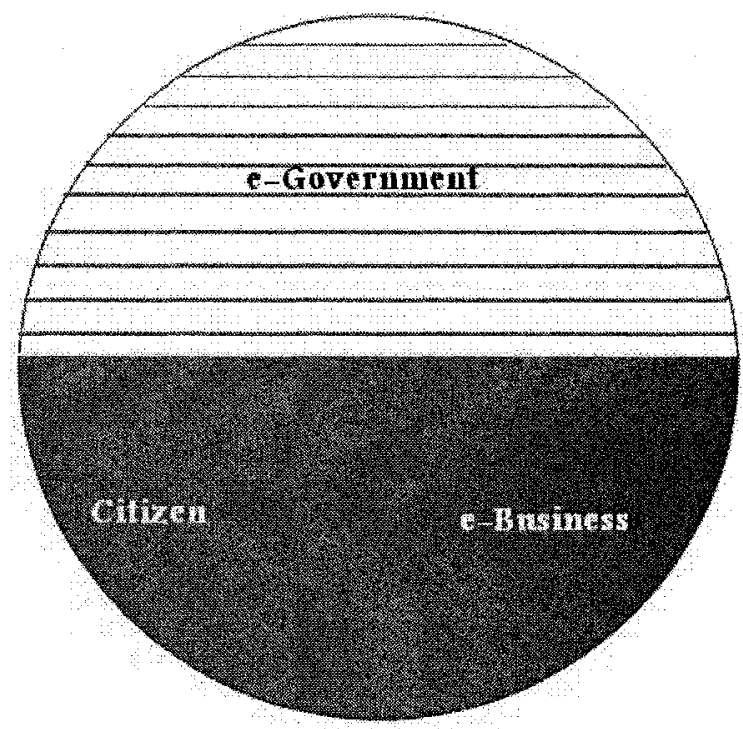

Fig. 4. The Hierarchical E-Government Model does not change the structure of the government, but simply introduces technology between the hierarchies.

\section{A New Framework for E-Governance: Jigsaw Model}

In the three prevalent e-government models, the e-economy is viewed as a product of three entities, namely; government, business, and citizen. The fundamental omission in these models is the absence of a core party which exists in today's economies and plays a major role within; the society. We propose a model which comprises of four parties including society in contrast to the three party models. Another characteristic of this model which draws parallels to a "jigsaw" is that neither party leads the rest. Instead, each party within the model complements the other and the progress and advancement of one mimics or follows the rest. This model aims for a government that does not sit on top of the citizens and businesses, rather stays in between (Fig. 5). The other significance of this model lies in the fact that e-government would not keep on evolving on its own whilst the other parties sit at bottom of the evolutionary chain. Before moving to the next stage of advancement any one party would make sure that the other parties are ready and able to move to the next stage as well.

The journey which a government takes towards a full transformation into an egovernment can be divided into number of phases, each phase marking a significant improvement in terms of structure and tools used. In a similar fashion an economy following the Jigsaw model divides the progress of a government towards egovernment into four stages. Each stage not only marks an advancement within the e-government but between the e-government and the other three parties in terms of technology, speed and relationship. In the following lines a detailed look at the four stages towards the deployment of an e-government is given. The other three parties would follow a somewhat similar path of evolution, but here only the e-government evolution is discussed. For businesses numerous staged models have been proposed 
over the last few decades following the adoption of ICTs in e-businesses and their supply chains such as Nolan Four [9], and Six Stages of Growth [10], Earl's Stages Model [11], and Hour Glass Supply Chain [4] respectively. The same or similar models would be just as applicable in the Jigsaw Model for transformation of businesses into e-businesses. Although these would require modifications to correspond to the development of four staged e-government model. On the other hand there hasn't been any major attempt to chalk out the stages in which a citizen and a society would or should evolve along with the ICT tools. Work is needed to develop a diverse set of staged models for citizens and societies as in case of ebusinesses. However, we have worked on four party models and their staged development but in the proceeding lines we are only discussing the four staged egovernment model; which is inclusive of e-democracy, e-service, e-management and e-government. However, we have mainly concentrated on the adoption of ICTs within the government and the development of relationship between the government and the citizen.



Fig. 5. The Jigsaw Model. This model as shown here consists of four parties. The main distinction of this model is inclusion of society as an individual party, and all parties complementing each other.

\subsection{Stage One}

This stage marks the beginning of implementation of the ICT tools by the government for the purpose of transformation of its governance and functionality. The government is considered to be in Stage One if it is implementing the following technologies. 
Internal Networks. The first step towards utilizing the benefits of ICTs is implementation of Local Area Networks (LAN) within the government offices followed by the Internet connectivity.

Website, Email and Information Dissemination. Second step is the development of a web presence and providing email addresses to the employees of the offices. Sharing information is the least technical and most important aspect in egovernment. However, ensuring the availability, accuracy, and timeliness of information is the biggest challenge [2]. Suitable tools like search options and site maps will need to be augmented with the provision of information on the web.

Electronic Forms. Third step is the availability of official forms on the Internet. Putting the forms up on the Internet does not demand high technical expertise nor is expensive. This should be high up on the priority list as it proves the willingness of the government to undertake the task of its procedural overhaul for convenience of the citizens.

Announcements. The fourth step is the periodic update of announcements' page.

Two Way Communications. Discussion boards need to be created for a two way communication between the officials and the citizens. It must be made sure that discussions are archived and have search options for future referencing and ease. Also, email addresses of the officials need to be made available on the web. These two tools would start the process of a two way direct communication between the public and the government officials.

Digital Data Collection. The process of data collection in digital format has to start in this stage. At this stage it will be done in a combination of employees typing in the data from physical documents and citizens entering some pieces of data online.

Tools for Help in Decision Making. Tools for helping and quickening the decision making process have to be implemented as well. Though primitive e-governance tools like spread sheets and budgeting software have been around for decades but they were mainly used by big organizations and at top levels of government hierarchy. Today however, the same software have fallen in their prices and house hold PCs are powerful enough to run them. Not only this but these off-the-shelf tools have been incremented by a wide array of variety. Appropriate measures have to be taken to implement these tools and make the civil servants accustomed with their usage.

Knowledge Management. Knowledge Management can be defined as the "management and use of collective knowledge or wisdom of an organization". The government has to start the implementation of knowledge management tools within the offices in this stage, be these basic ones. 
Pilot Project. The stage one of e-government ends at testing of a pilot project for an e-service with e-transaction. Selection of the service can be based on any criterion like that of maximum users, easiest to transform into e-service, etc.

\subsection{Stage Two}

A government is said to be in stage two when the culture of e-transactions has started and majority of the citizens have access to the Internet. The ICT tools that a Stage Two e-government would be using and the level of relationship between the egovernment and the citizen are discussed below.

E-Services and Intra-Office Networks. The government will have to take the initiatives to begin the process of transformation of its services into e-services. The office LANs would need to be technologically advanced along with backup capabilities. Appropriate security tools have to be utilized for the said purpose. Furthermore the process of integration of the networks of different branches of same office has to be started. This will be an integral part for effective provisioning of eservices.

Information Dissemination. The amount of information available at every department's website would be increased and augmented with details related to the official procedures, budgets, and expenditures. Search options and searching would need to be advanced to counter the time taken for sorting out the information through the ever increasing data.

Electronic Forms. The online downloadable forms have to evolve to accommodate for online submission and e-transactions.

Announcements and Updates. The websites are to be updated at regular intervals and should materialize the capability of sending automated emails to registered users. It is pointed out here that if the websites are not regularly updated the users would not be interested in re-visiting.

Two Way Communication. Two way communication is evolved to allow for live chats with the officials on special occasions. This will start the culture of citizens and officials chatting with each other in real time. This will be the prelude to teleconferencing.

Digital Data Collection. In Stage One majority of the data was being entered into the database by the employees. However, now the system would have to be upgraded so that the data is automatically generated from electronically submitted forms, information sorted and stored by intelligent software. The process of conversion of backlog data into digital format should be started as well. 
Decision Modeling Tools. The decisions made within the offices would be taking advantage of Expert systems; the digital information being utilized in policy making and decision making.

Knowledge Management. Custom knowledge management tools would be seen being employed in more and more government offices. This will be the advancement in knowledge management area.

Government Portal Sites and Value Added Services. The government should develop an e-portal at this stage. E-Portal is a site which brings together numerous content providers, provides information, and develops a closer relationship between the government and the citizen. Main aim of E-Portal is to have one site from where users can get all the information. The finest examples of e-portal are FirstGov (www.firstgove.gov) of America, and eCitizen (www.ecitizen.gov.sg) of Singapore.

Unique ID. The government will have to take steps in assigning a unique ID to every citizen of the country. This can be done based on ID card, passport, driving license or birth certificate number. The same ID should also be used to provide a national email address to every citizen however; the email address should have the ability to forward the emails. This will create a direct communication link between the government and the citizen. The regulations would be needed to make sure private enterprises and citizens are not allowed to use this email address and procedures would be needed so that government employees can't misuse this facility. This would also be the first step towards e-voting and would be very useful in providing numerous statistical data such as how many citizens have access to the Internet.

Integration and Automated Exchange of Data - Pilot Project. The Stage Two will end at testing of a pilot project for automated exchange of data between two different offices, taking the government into next level of e-government.

\subsection{Stage Three}

By the start of this stage every government office would be online and data would be automatically sorted and sent to the respective agencies. Majority of the citizens are expected to be online as well.

Development of an Intra-National Network and Automated Exchange of Data. The first development in Stage Three should be the upgradation of government networks to accommodate automated transfer of data between different government offices. Two sites for e-government integration are Australia's state of Victoria's maxi (www.maxi.com.au) and eCitizen center of Singapore.

Information Dissemination. The necessary infrastructure developed is now capable of all information being stored electronically. The only addition left would be the video streaming and real time video streaming. 
Announcements and Updates. The announcement system should become intelligent at this stage. An example of intelligent announcement in case of students is software's recognition of which email addresses belong to students of PreEngineering courses and then comparing the marks with the university merit lists it would send emails regarding the admission dates to the qualifying students.

Two way communication. The two way communication should be evolved to implement teleconferencing as a normal means of communication. However, the other means of two-way communication would still be available.

E-Democracy. By now the security problems and encryption techniques as well as the unique identification of the citizens would have been achieved. Theoretically the government should be ready to implement the e-democracy which requires capabilities for e-voting and real time chatting with the constituents over the Internet.

\subsection{Stage Four}

When the entire government is integrated into one giant network with automated flow of information the government would be considered in Fourth Stage. By now every governmental service would be available electronically. This stage wouldn't implement any new e-services but the concentration would be on upgrading of the technology of existing e-services. The other significant advancement in this stage would be the start of integration of different e-governments, the ultimate aim of today's e-governance.

M-Commerce. By the time the e-governance reaches Stage Four, its contemporary e-business block would have stepped into $\mathrm{m}$-commerce (mobile commerce). Public would have become accustomed to surfing the net on the move, e.g. from Internet enabled cars, mobile phones, etc. It would be imperative for the e-government to evolve just as well - into m-government.

Inter Government Integration. Turning the world into one giant global village is the ultimate dream for tomorrow and by the time an e-government arrives at the end of the road of the fourth stage it would be ready to integrate with the global network of e-governments.

\section{Conclusion}

Internet is a tool that is equally and easily accessible both by the poor and the rich. This tool also facilitates the development and transformation process coexisting with participation, transparency and accountability. As President Bill Clinton said, "The Internet has the potential to strengthen our democracy and to make government more open, efficient, and user-friendly" [1]. 
Developing countries need to tap the vast potential - employment, trade and services - that the ICT sector offers in addition to bringing greater transparency and ease. The utilization of the surging potential in the ICT sector is crucially linked with transforming governmental functions to e-government albeit in phases and with pilot projects.

The technology available is neither expensive nor complicated. Development of e-services does not require complicated processes either. A functioning egovernment is feasible in every corner of the globe. This paper has been an attempt in this direction.

\section{References}

1. J. H. Birnbaum, Death to Bureaucrats, Good News for the Rest of Us: As Government Moves Online, Jobs Will Disappear. But you Won't Have to Spend Hours Renewing a Driver's License Fortune 142 (10) (26 June, 2000).

2. Gartner Group: E-Government Security: Voting on the Internet. Research Notes, Strategic Planning Assumption (18 January 2000).

3. Gartner Group: Key Issues in E-Government Strategy and Management. Research Notes, Key Issues (23 May 2000).

4. A. Ghayur, Utilizing the Surging Potential of E-Commerce: A Case of Hour Glass Supply Chain, Pakistan Development Review 42, 607-625 (Winter 2003).

5. D. L. McClure, Electronic Government: Federal Initiatives are Evolving Rapidly but They Have Significant Challenges (GAO/T-AIMD/GGD-00-179 Testimony, Washington, DC, 22 May 2000).

6. Perri 6, E-Governance: Do Digital Aids Make a Difference in Policy Making? In: Designing E-Government, edited by J. E. J. Prins (Kluwer Law International, The Hague, 2001) Pages: 7-27.

7. Perri 6, E-Governance: Styles of Political Judgment in the Information Age Polity (Palgrave Macmillan, Basingstoke, 2004).

8. G. N. L. Stowers, Commerce Comes to Government on the Desktop: E-Commerce Applications in the Public Sector, in: E-Government 2001, edited by M. A. Abramson and G. E. Means (Rowman and Littlefield Publishers, Lanham, 2001).

9. R. L. Nolan, Managing the Computer Resource: A Stage Hypothesis, Communications of the ACM 16, 399-407 (1973).

10. R. L. Nolan, Managing the Crisis in Data Processing Harvard Business Review Mar-Apr, 115-126 (1979).

10. M. J. Earl, Evolving the E-Business Business Strategy Review 11, 33-38 (2000). 